\section{Caracterização de Rickettsia spp. circulante em foco silencioso de febre maculosa brasileira no Município de Caratinga, Minas Gerais, Brasil}

\author{
Characterization of Rickettsia spp. circulating \\ in a silent peri-urban focus for Brazilian spotted \\ fever in Caratinga, Minas Gerais, Brazil
}

\author{
Luciane Daniele Cardoso 1 \\ Renata Nascimento Freitas 1 \\ Cláudio Lísias Mafra ${ }^{2}$ \\ Cristiane Vilas Boas Neves 1 \\ Fátima Cristina Bacellar Figueira 3 \\ Marcelo Bahia Labruna 4 \\ Solange M. Gennari 4 \\ David Hughes Walker 5 \\ Márcio Antônio Moreira Galvão ${ }^{1}$
}

\footnotetext{
1 Escola de Nutrição, Universidade Federal de Ouro Preto, Ouro Preto, Brasil.

2 Departamento de Bioquímica e Biologia Molecular, Universidade Federal de Viçosa Viçosa, Brasil.

3 Centro de Estudo de Vectores e Doenças Infecciosas, Instituto Nacional de Saúde Dr. Ricardo Jorge, Ánas de Moura, Portugal. 4 Faculdade de Medicina Veterinária, Universidade de São Paulo, São Paulo, Brasil. 5 University of Texas Medical Branch, Galveston, U.S.A.

Correspondência M. A. M. Galvão Escola de Nutrição, Universidade Federal de Ouro Preto. Campus Universitário Morro do Cruzeiro Ouro Preto, $M G$ 35400-000, Brasil. magalvao@uai.com.br
}

\begin{abstract}
The present study was intended to characterize Rickettsia spp. circulating in arthropod vectors in Caratinga, Minas Gerais, Brazil, by PCR and to investigate the presence of antibodies against the spotted fever Rickettsiae group (SFRG) in dogs and horses. 2,610 arthropods were collected and taxonomically identified. DNA samples obtained from these vectors were submitted to PCR and cycle-sequenced. Ctenocephalides and Amblyomma cajennense showed sequences presenting $100.0 \%$ homology with R. felis. A sequence obtained from Rhipicephalus sanguineus showed 99.0\% homology with R. felis, and a sequence from A. cajennense showed $97.0 \%$ homology with R. honei and R. rickettsii. Canine (73) and equine (18) serum samples were tested by indirect fluorescent antibody (IFA) using R. rickettsii antigen. Only three of the equine sera tested (17.0\%) had positive antibody titers. Molecular detection of rickettsiae species potentially pathogenic to humans in arthropod vectors and the presence of seroreactivity to SFRG in horses show the risk of transmission of rickettsiosis in this area and the need to maintain continuous epidemiological surveillance for rickettsial diseases.
\end{abstract}

Rickettsia; Rickettsia Infectious; Spotted Fever; Arthropod Vectors

\section{Introdução}

As riquétsias patogênicas constituem um grupo de microrganismos com características de bactérias gram-negativas, intracelulares obrigatórias responsáveis por várias doenças conhecidas como riquetsioses, que são transmitidas ao homem por meio da picada de artrópodes hematófagos, tais como carrapato, pulga e piolho 1,2. Casos humanos de infecção por bactérias do gênero Rickettsia têm sido descritos em vários países da América do Sul nos últimos vinte anos.

O Brasil apresenta histórico de doença riquetsial desde a década de 20 , sendo a febre maculosa brasileira a mais severa das riquetsioses descritas, ocorrendo principalmente no Sudeste do país. Em Minas Gerais tem-se registrado, desde a década de 80 , a ocorrência de inúmeros casos da doença na forma de epidemias em áreas rurais e peri-urbanas, com predominância nos Vales do Jequitinhonha, do Mucuri e do Rio Doce 3.

A introdução de técnicas da biologia molecular na investigação de doenças riquetsiais tem assumido grande importância na detecção de várias espécies do gênero Rickettsia em vetores, humanos e animais, permitindo a caracterização de espécies já conhecidas como a $R$. rickettsii e outras recentemente reconhecidas como a R. felis. Em 2002, casos humanos de riquetsiose causada por $R$. felis foram descritos 
no Estado de Minas Gerais, sendo este agente detectado por reação em cadeia da polimerase (PCR) em pulgas do gênero Ctenocephalides 4.

Em 1992 foi registrada através da Secretaria Estadual de Saúde de Minas Gerais (SES-MG), a existência de um foco peri-urbano de riquetsioses expressivo em termos de ocorrência de casos, no Município de Caratinga, localizado no Vale do Rio Doce ${ }^{3}$. No período de junho a outubro de 1992, a SES-MG notificou a ocorrência de 15 óbitos nesse município, sendo que, na ocasião, a hipótese de febre maculosa como causadora dos óbitos foi baseada em critérios clínico-epidemiológicos e laboratoriais.

Motivado pelas características do foco mencionado, Galvão ${ }^{3}$ estudou o comportamento da febre maculosa brasileira no Município de Caratinga, e por meio de inquérito sorológico registrou uma soro-prevalência de $2 \%$ em humanos, $25 \%$ em cães e $53 \%$ em eqüinos, utilizando a reação de imunofluorescência indireta (RIFI) realizada com antígeno específico de $R$. rickettsii. Desde então e até os dias atuais, apenas um caso novo de febre maculosa brasileira foi registrado naquele município, logo no primeiro ano após o surto. Deste modo, como contribuição para um melhor conhecimento do ciclo natural das riquétsias, o presente trabalho pretendeu reavaliar o foco peri-urbano de Caratinga, aparentemente silencioso, por meio da investigação de infecção por bactérias do gênero Rickettsia na população de artrópodes vetores encontrados em animais vivendo nos domicílios e peri-domicílio. Para tanto, foi utilizada a sorologia por RIFI e a PCR com o objetivo de melhor conhecer a dinâmica da infecção dos vetores e hospedeiros por riquétsias na referida área, e estimar o risco ao qual está submetida sua população, contribuindo, dessa forma, para o conhecimento da epidemiologia das riquetsioses.

\section{Métodos}

A coleta de vetores (pulgas e carrapatos) foi realizada em cães, gatos, eqüinos e em pastagens do bairro da Cadeia, área peri-urbana do Município de Caratinga, Minas Gerais, por uma equipe devidamente treinada do escritório da Fundação Nacional de Saúde (FUNASA) em Caratinga, em parceria com a equipe executora deste projeto. Os ectoparasitos em fase parasitária e de vida livre foram coletados no período de maio de 2002 a abril de 2003. Os carrapatos e pulgas em fase parasitária foram coletados pela busca na superfície do corpo dos animais presentes no domicílio e peri-domicílio. A co- leta foi feita manualmente e os artrópodes foram acondicionados em recipiente apropriado segundo o local e animal de origem. Carrapatos de vida livre foram coletados usando-se a técnica de arrasto de flanela e acondicionados da mesma forma.

Os artrópodes foram identificados taxonomicamente utilizando-se a chave dicotômica e pictórica descrita por Aragão \& Fonseca ${ }^{5}$ para carrapatos adultos e critérios morfológicos para identificação das pulgas 6 , agrupados de acordo com estádio evolutivo e animal de origem em lotes contendo 1 a 8 indivíduos por lote e submetidos à extração de DNA pelo método do fenol/clorofórmio, conforme descrito anteriormente 7 .

O DNA extraído foi amplificado por meio da PCR, usando-se uma reação dúplex contendo dois pares de iniciadores gênero específicos, um que amplifica uma seqüência do gene da proteína citrato sintase ( $g l t A$ ) e outro que amplifica uma seqüência do gene da proteína interna de membrana, $17 \mathrm{KDa}$ (17KDa omp), ambas gênero específica 8,9,10. De maneira a otimizar as análises por PCR, cada reação foi realizada com um pool contendo 50ng de seis diferentes amostras de DNA. Assim, cada tubo de reação continha 300ng de DNA, tampão Tris$\mathrm{HCl} 20 \mathrm{mM} \mathrm{pH} \mathrm{8,4,} \mathrm{KCl} \mathrm{50mM,} \mathrm{MgCl}_{2} 1,5 \mathrm{mM}$, 20 pmoles de cada iniciador e 1,25 unidade de Taq DNA polimerase (Invitrogen Life Technologies, Estados Unidos) em um volume final de 50mL. A mistura de reação foi submetida à desnaturação inicial a $94^{\circ} \mathrm{C}$ por 5 minutos, seguida por 30 ciclos de anelamento a $55^{\circ} \mathrm{C}$ por $3 \mathrm{minu}$ tos, extensão a $72^{\circ} \mathrm{C}$ por 2 minutos, desnaturação a $95^{\circ} \mathrm{C}$ por 1 minuto e uma extensão final a $72^{\circ} \mathrm{C}$ por 7 minutos. A cada experimento foi adicionado um tubo contendo DNA obtido de células Vero infectadas experimentalmente com $R$. parkeri (controle positivo) e um tubo contendo todos os reagentes exceto DNA (controle negativo). Os produtos amplificados foram visualizados em gel de poliacrilamida $8 \%$ corado pela prata 11 . Os produtos $(5 \mu \mathrm{L})$ que não apresentaram amplificação nesta reação foram submetidos a uma reamplificação na qual foi utilizado um par de iniciadores internos para o gene $17 \mathrm{kDa}$ (full nested $\mathrm{PCR}$ ). As condições da segunda reação foram semelhantes à primeira, sendo que a temperatura de anelamento foi diminuída para $50^{\circ} \mathrm{C}$. A seqüência dos iniciadores utilizados e o tamanho dos produtos amplificados estão apresentados na Tabela 1. Os produtos de PCR que apresentaram resultado positivo foram clonados no vetor pCR $\AA^{\circledR}$ 2.1-TOPO do kit TOPO TA Cloning ${ }^{\circledR}$ da Invitrogen, purificados utilizando-se o kit Wizard ${ }^{\circledR}$ Plus SV 
Seqüência dos iniciadores e tamanho dos produtos amplificados nas reações de PCR.

\begin{tabular}{|c|c|c|c|}
\hline Iniciador & Gene & Seqüência nucleotídica (5'_3') & $\begin{array}{l}\text { Tamanho do produto } \\
\text { amplificado }\end{array}$ \\
\hline \multicolumn{4}{|l|}{ Cs877p } \\
\hline \multirow[t]{2}{*}{ Cs1258n } & gltA & GGGGGCCTGCTCACGGCGG & \\
\hline & & ATTGCAAAAAGTACAGTGAACA & $381 \mathrm{pb}$ \\
\hline \multicolumn{4}{|l|}{ 17KDa 1} \\
\hline \multirow[t]{2}{*}{ 17KDa 2} & $17 \mathrm{KDa}$ omp & GCTCTTGCAACTTCTATGTT & \\
\hline & & CATTGTTCGTCAGGTTGGCG & $434 \mathrm{pb}$ \\
\hline \multicolumn{4}{|l|}{ N 17kDa 1} \\
\hline \multirow[t]{2}{*}{ N $17 \mathrm{kDa} 2$} & $17 \mathrm{KDa}$ omp & CATTACTTGGTTCTCAATTCGGT & \\
\hline & (nested) & GTTTTATTAGTGGTTACGTAA & $232 \mathrm{pb}$ \\
\hline
\end{tabular}

Minipreps DNA Purification System da Promega e ambas as fitas foram seqüenciadas com o iniciador universal usando o kit de seqüenciamento ABI PRISM BigDye III Terminator Cycle Sequencing Ready Reaction da Applied Biosystems em um seqüenciador automático de DNA (ABI PRISM). As seqüências obtidas de ambas as fitas foram alinhadas utilizando-se o programa ClustalW (disponível no endereço eletrônico: http://www.workbench.sdsc.edu), editadas usando-se o programa Chromas (http://www. technelysium.com.au/chromas.html) e submetidas à pesquisa de homologia com outras seqüências depositadas no GenBank, utilizando-se o programa BLASTn 12.

Amostras de $10 \mathrm{ml}$ de sangue foram coletadas por meio de venocentese da cefálica em cães ou da jugular em eqüinos presentes no domicílio e peri-domicílio do bairro da Cadeia, e identificados de acordo com o animal de origem e proprietário. Foram coletados 91 soros de animais, sendo 73 amostras provenientes de cães e 18 de eqüinos. O soro foi obtido por meio de centrifugação das amostras a 3.000rpm por 10 minutos e congelados em tubos de polipropileno a $-20^{\circ} \mathrm{C}$, até o momento da análise. Alíquotas de soro diluídas em tampão fosfato (PBS pH 7,2 ) foram depositadas sobre lâminas contendo antígeno específico de $R$. rickettsii e incubadas a $37^{\circ} \mathrm{C}$. A cada lâmina foi adicionado o conjugado Fluorine $H$ (BIOLAB) anticão e anticavalo, marcados com isotiocianato de fluoresceína. Os soros foram testados na diluição 1:64, sendo este o ponto de corte utilizado 13 .

\section{Resultados}

Foram coletados um total de 2.610 ectoparasitos, dentre eles, 2.241 carrapatos $(85,5 \%)$ e 379 pulgas $(14,5 \%)$. Os carrapatos foram encontrados nos três estádios de desenvolvimento (larvas, ninfas e adultos), sendo que as formas adultas (1.535 indivíduos) compuseram $68 \%$ do total. Na identificação taxonômica dos carrapatos adultos foram reconhecidas as espécies Amblyomma cajennense (73\%), Riphicephalus sanguineus (23\%) e Anocentor nitens (4\%) parasitando eqüinos e cães. As pulgas foram identificadas como pertencentes ao gênero Ctenocephalides e foram encontradas parasitando cães e gatos.

De um total de 119 pools de DNA analisados por PCR, 16 apresentaram resultado positivo. Destes, 6 pools foram provenientes de DNA de pulgas e 10 de DNA de carrapatos. A Figura 1 retrata um gel no qual estão apresentados resultados da análise de quatro das amostras testadas.

Das amostras positivas, foram realizados o seqüenciamento e pesquisa de homologia. Uma amostra proveniente de Ctenocephalides coletada em cão apresentou $100 \%$ de homologia com R. felis. Duas seqüências obtidas de A. cajennense (oriundos de cavalo) e $R$. sanguineus (cão) apresentaram $100 \%$ e $99 \%$ de homologia com R. felis, respectivamente. A seqüência de uma amostra de $A$. cajennense coletada em cavalo revelou homologia de $97 \%$, tanto com $R$. rickettsii quanto com $R$. honei (Tabela 2 ).

Nenhum dos soros de cães analisados $(n=$ 73) apresentou resultado positivo à RIFI, enquanto que $3 / 18$ dos soros de eqüinos (17\%) mostraram-se positivos nos títulos 1:64 $(\mathrm{n}=1)$ e $1: 128(n=2)$. 
Figura 1

Gel de poliacrilamida $8 \%$ corado pela prata de produto amplificado de PCR dúplex usando os pares de iniciadores Cs877p, Cs1258n e 17KDa 1, e 17KDa 2;

e produto amplificado de full nested PCR usando o par de iniciadores $\mathrm{n} 17 \mathrm{KDa}$ 1 e n17KDa 2.

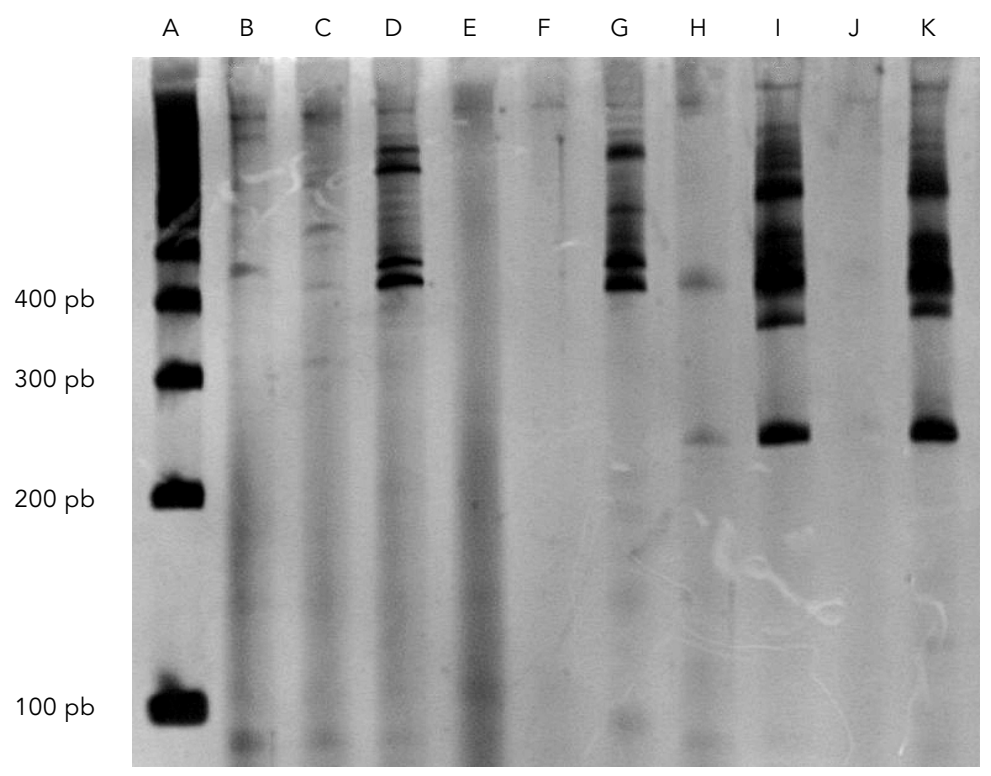

Nota: Canaleta A - marcador de peso molecular (100 pb ladder); Canaletas $B$ a E - PCR dúplex de amostras de campo; Canaleta F- controle negativo (dúplex); Canaleta $\mathrm{G}$ - controle positivo (dúplex); Canaletas $\mathrm{H}$ e I - nested PCR das amostras B e C, respectivamente; Canaleta $\mathrm{J}$ - controle negativo (nested PCR); Canaleta $\mathrm{K}$ - controle positivo nested PCR.

\section{Discussão}

A coleta de ectoparasitas de vida livre e parasitando cães, gatos e eqüinos do domicílio e peri-domicílio do bairro Candeias em Caratinga foi realizada no período de maio de 2002 a abril de 2003, com coletas bimensais, o que permitiu a cobertura da variação sazonal da distribuição dos estádios evolutivos do carrapato. Todas as pulgas que infestavam cães e gatos eram do gênero Ctenocephalides, que apresenta ampla distribuição mundial e variado espectro de hospedeiros, sendo um dos parasitas mais comuns em cães e gatos, além de se alimentar também em humanos 14,15.

A ocorrência de pulgas do gênero Ctenocephalides infectadas com $R$. felis, detectadas por meio de PCR, constitui evidência de que a $R$. felis pode ser uma espécie de importância epidemiológica na região estudada, indicando uma possibilidade de surgimento de outras riquetsioses humanas na região, além de atestar a po- tencialidade das pulgas como vetores na transmissão das riquetsioses. $R$. felis, inicialmente designada agente ELB, é uma bactéria transmitida por pulgas do gênero Ctenocephalides, as quais também atuam como reservatórios devido à transmissão transovariana $16,17,18$. Sua distribuição está ligada à presença do inseto vetor, e até o presente momento foram detectadas em populações de pulgas nas Américas do Sul e do Norte e Europa 4,14. A infecção humana por essa riquétsia tem sido demonstrada no México 19, Brasil 20 e Europa 21.

O A. cajennense, principal espécie de carrapato encontrada neste trabalho, é encontrada em abundância em todos os Estados das regiões Sudeste e Centro-oeste no Brasil, porém com distribuição limitada nas demais regiões, sendo a principal espécie de carrapato encontrada parasitando seres humanos no centro-sul brasileiro 22,23,24 e considerada o principal vetor da febre maculosa 25 . O fato de uma seqüência de DNA amplificado de A. cajennense ter apresentado a mesma homologia tanto para $R$. rickettsii e $R$. honei, pode ser explicado pela metodologia empregada, uma vez que os iniciadores utilizados para o seqüenciamento (17KDa) amplificam um fragmento altamente conservado dentro do gênero Rickettsia. De qualquer maneira, tanto $R$. rickettsii quanto $R$. honei, são espécies do grupo da febre maculosa capazes de causar doença ao homem, embora a R. honei não tenha sido descrita no Brasil.

$\mathrm{O}$ achado de carrapatos da espécie $R$. sanguineus infectado por $R$. felis é inédito na literatura, enquanto a presença de $R$. felis em carrapatos da espécie $A$. cajennense foi descrita anteriormente 26. Esses últimos achados são interessantes, já que no mundo das riquetsioses não tem sido descrita a presença da mesma bactéria em mais de um vetor. Acreditamos que, na verdade, as técnicas de isolamento e identificação utilizadas anteriormente não apresentavam o potencial de detecção da PCR, que é capaz de detectar a presença de fentogramas de DNA. Assim, é possível que agora estejamos apenas detectando um evento que não é novo, mas que não havia sido descrito anteriormente. Além de carrapatos da espécie A. cajennen$s e$, a espécie $R$. sanguineus foi encontrada de maneira importante em cães e cavalos, o que chama a atenção para a possibilidade de participação desses animais na epidemiologia das riquetsioses na região. Assim, o estudo sorológico desses hospedeiros potenciais é importante, pois pode fornecer informações sobre o ciclo epidemiológico da doença. Magnarelli et al. 27 observaram que a prevalência de carrapatos infectados detectados por imunofluores- 
Homologia de seqüências amplificadas de DNA de ectoparasitos coletados em animais domésticos.

Caratinga, Minas Gerais, Brasil, no período de maio de 2002 a abril de 2003.

\begin{tabular}{llll}
\hline Pool & Animal de origem & Gênero/espécie & Homologia encontrada \\
\hline 06 & cão & Ctenocephalides spp. & $100 \%$ com R. felis \\
21 & cavalo & Amblyomma cajennense & $100 \%$ com R. felis \\
22 & cão & Rhipicephalus sanguineus & $99 \%$ com R. felis \\
28 & cavalo & Amblyomma cajennense & $97 \%$ com R. rickettsii e R. honei \\
\hline
\end{tabular}

cência direta é a mesma tanto em áreas endêmicas como em áreas não-endêmicas, fato este que reduz aparentemente a importância do carrapato como indicador de atividade riquetsial em uma determinada área, isto é, embora a presença do ixodídeo infectado seja necessária, ela em geral não seria suficiente para produzir casos humanos. Entretanto devem ser considerados os casos de alta infestação por carrapatos que podem alterar essa relação.

Dessa forma, para que haja atividade riquetsial poderia ser necessária a coexistência de uma relação de positividade entre vetores, hospedeiros e reservatórios, incluindo animais silvestres. O cão, assim como o cavalo, é um animal próximo do homem e ambos podem ter importante papel na cadeia epidemiológica da febre maculosa. A ausência de sorologia positiva no cão, associada à ausência de casos humanos diagnosticados no local nos últimos 12 anos parece ser importante para a caracterização de foco silencioso. No entanto, a presença de sorologia positiva em cavalos, considerando o papel desses animais como sentinela, e a detecção molecular de riquétsias patogênicas em artrópodes vetores, apontam para necessidade de se manter um sistema de vigilância epidemiológica no local e na região. Associado a isso, há o fato desses animais serem de livre movimentação, criados soltos e utilizados para o transporte, podendo dispersar carrapatos infectados, os quais podem se estabelecer em outras áreas provocando, assim, o surgimento de novos focos.

Assim, embora tenha sido detectada a presença de anticorpos anti-riquétsias do grupo da febre maculosa no cavalo, e apesar da detecção molecular de riquétsias patogênicas em artrópodes vetores, não há registro sistemático de casos de febre maculosa na região nos últimos 12 anos, o que coloca o município num nível de baixa transmissão, embora o risco ainda exista, devendo-se manter o sistema de vigilância epidemiológica e acarológica no local e região.

\section{Resumo}

O objetivo deste trabalho foi caracterizar Rickettsia spp. circulante em artrópodes vetores no Município de Caratinga, Minas Gerais, Brasil, por meio da PCR, e investigar a presença de anticorpos para riquétsias do grupo da febre maculosa em cães e eqüinos. 2.610 ectoparasitos foram coletados e identificados taxonomicamente. Amostras de DNA obtidas desses vetores foram submetidas à PCR e seqüenciamento. Em pulgas do gênero Ctenocephalides e em carrapatos Amblyomma cajennense foram identificadas seqüencias com 100\% de homologia com R. felis. Em carrapatos Rhipicephalus sanguineus uma seqüência apresentou 99\% de homologia com $\mathrm{R}$. felis e uma seqüência obtida de A. cajennense apresentou $97 \%$ de homologia com R. honei $e$ R. rickettsii. Soros de cães (73) e de eqüinos (18) foram submetidos à imunofluorescência indireta (RIFI) usando-se antígeno de R. rickettsii. Apenas três dos soros de eqüinos (17\%) mostraram-se positivos. A detecção molecular de riquetsias potencialmente patogênicas ao homem em vetores e a presença de sororeatividade para riquetsias do grupo da febre maculosa em eqüinos, demonstram o risco de transmissão de riquetsioses nessa área e a necessidade de se manter um sistema contínuo de vigilância epidemiológica.

Rickettsia; Rickettsioses; Febre Maculosa; Vetores Artrópodes 


\section{Colaboradores}

L. D. Cardoso realizou a revisão bibliográfica, participou de todos os experimentos e realizou a análise e discussão dos dados. R. N. Freitas e C. V. B. Neves realizaram a extração de DNA, as reações de amplificação, as clonagens e os seqüenciamentos. C. L. Mafra, M. B. Labruna e S. M. Gennari colaboraram no planejamento do trabalho de campo e na coleta de vetores e sangue dos cães e eqüinos e C. L. Mafra foi responsável pela classificação taxonômica dos vetores, colaborou nos experimentos de sorologia, na análise e discussão dos dados. F. C. B. Figueira colaborou no cultivo de células Vero infectadas com Rickettsia parkeri e na obtenção de DNA para os controles positivos da PCR. D. H. Walker colaborou na obtenção dos antígenos para a sorologia, na análise e confirmação dos seqüenciamentos e na discussão dos resultados. M. A. M. Galvão coordenou o projeto e foi responsável pelo desenho do mesmo, colaborou nos experimentos de sorologia, na análise e discussão dos dados. L. D. Cardoso, R. N. Freitas e M. A. M. Galvão elaboraram a versão final do artigo.

\section{Referências}

1. Hoogstraal H. Ticks in relation to human diseases caused by Rickettsia species. Ann Rev Entomol 1967; 12:377-420.

2. Friedhoff KT. Interaction between parasite and tick vector. Int J Parasitol 1990; 20:525-35.

3. Galvão MAM. Febre maculosa em Minas Gerais: um estudo sobre a distribuição da doença no estado e seu comportamento em área de foco periurbano [Tese de Doutorado]. Belo Horizonte: Universidade Federal de Minas Gerais; 1996.

4. Oliveira RP, Galvão MAM, Mafra CL, Chamone CB Calic SB, Silva SU, et al. Rickettsia felis in Ctenocephalides spp. fleas, Brazil. Emerg Infec Dis 2002; 8:317-9.

5. Aragão HB, Fonseca F. Notas de ixidologia. VIII Lista e chave para os representantes da fauna ixodológica brasileira. Mem Inst Oswaldo Cruz 1961; 59:115-29.

6. Ruppert EE, Fox RS, Barnes RB. Invertebrate zoology: a functional evolutionary approach. $7^{\text {th }} \mathrm{Ed}$. Belmont: Brooks Cole Thomson; 2004.

7. Billings AN, Yu XJ, Teel PD, Walker DH. Detection of spotted fever group Rickettsia in Amblyomma cajennense (Acari: Ixodidae) in South Texas. J Med Ent 1998; 35:474-8.

8. Azad AF, Webb L, Carl M, Dasch GA. Detection of Rickettsiae in arthropod vectors by DNA amplification using the polymerase chain reaction. Ann NY Acad Sci 1990; 590:557-63.

9. Webb L, Carl M, Malloy DC, Dasch GA, Azad AF Detection of murine typhus infection in fleas by using the polymerase chain reaction. J Clin $\mathrm{Mi}$ crobiol 1990; 28:530-4.

\section{Agradecimentos}

Agradecemos ao laboratório Referência Estadual para Rickettsioses da Fundação Ezequiel Dias (FUNED) em Belo Horizonte, Minas Gerais, onde foram realizadas as análises sorológicas; à Secretaria Municipal de Saúde de Caratinga e ao veterinário Álvaro Tapias que colaboraram com a infra-estrutura e material utilizado no trabalho de campo.

10. Schriefer ME, Sacci JB, Dumler S, Bullen MG, Azad AF. Identification of a novel rickettsial infection in a patient diagnosed with murine typhus. J Clin Microbiol 1994; 32:949-54.

11. Sanguinetti CJ, Dias Neto E, Simpson AJ. Rapid silver staining and recovery of PCR products separated on polyacrilamide gels. Biotechn 1994; 17:914-21.

12. Altschul SF, Madden TL, Schäffer AA, Zhang J, Zhang Z, Miller W, et al. Gapped BLAST and PSI BLAST: a new generation of protein database search programs. Nucleic Acids Res 1997; 25:3389402.

13. Dumler SJ, Walker DH. Diagnostic tests for Rocky Mountain spotted fever and other rickettsial diseases. Dermatol Clin 1994; 12:25-36.

14. Márquez FJ, Muniain MA, Pérez JM, Pachón J. Presence of Rickettsia felis in the cat flea form southwestern Europe. Emerg Infect Dis 2002; 8:89-91.

15. Kenny MJ, Birtles RJ, Day MJ, Shaw SE. Rickettsia felis in the United Kingdom. Emerg Infect Dis 2003; 9:1023-4.

16. Azad AF, Sacci Jr. JB, Nelson WM, Dasch GA Schmidtmann ET, Carl M. Genetic characterization and transovarial transmission of a typhuslike rickettsia found in cat fleas. Proc Natl Acad Sci USA 1992; 89:43-6.

17. Higgins JA, Radulovic S. Schiefer ME, Azad AF Rickettsia felis: a new specie of pathogenic Rickettsia isolated from cat fleas. J Clin Microbiol 1996; 34:671-4.

18. Bouyer DH, Stenos J, Crocquet-Valdes PA. Rickettsia felis: molecular characterization of a new 
member of the spotted fever group. Int J Syst Evol Microbiol 2001; 51:339-47.

19. Zavala-Velazquez JE, Ruiz-Sosa JA, Vado-Solis IRA, Billings NA, Walker DH. Serologic study of the prevalence of rickettsiosis in Yucatan: evidence for a prevalent spotted fever group rickettsiosis, Am J Trop Med Hyg 1999; 61:405-8.

20. Raoult D, La Scola B, Enea M, Fournier PE, Roux V, Fenollar F, et al. A flea associated Rickettsia pathogenic for humans. Emerg Infect Dis 2001; 7:73-81

21. Richter J, Fournier PE, Petridou J, Haussinger D, Raoult D. Rickettsia felis infection acquires in Europe and documented by polymerase chain reaction. Emerg Infect Dis 2002; 8:207-8.

22. Guimarães JH, Tucci EC, Barros-Battesti, DM. Ectoparasitos de importância veterinária. São Paulo: Editora Plêiade; 2001.

23. Labruna MB, Kerber CE, Ferreira F, Faccini JLH, De Waal DT, Gennari SM. Risk factors to tick infestations and their occurence horses in the State of São Paulo, Brazil. Vet Parasitol 2001; 97:1-14.
24. Secretaria de Estado da Saúde. Manual de vigilância acarológica. São Paulo: Secretaria de Estado da Saúde; 2004.

25. Dias E, Martins AV. Spotted fever in Brazil: a summary. Am J Trop Med 1939; 19:103-8.

26. Galvão MAM, Bouyer DH, Olano JP, CerqueiraLeite R, Walker DH. Rickettsia felis in Amblyomma cajennense ticks, Brazil. In: International Conference on Rickettsiae and Rickettsial Diseases, Book of Abstracts. Ljubljana: MIDA/Institute of Microbiology and Immunology, Medical Faculty; 2002. p. 103.

27. Magnarelli LA, Anderson JF, Philip RN, Burgdorfer W, Casper EA. Endemicity of spotted fever group rickettsiae in Connecticut. Am J Trop Med Hyg 1981; 30:239-52.

Recebido em 27/Jun/2005

Versão final reapresentada em 08/Nov/2005

Aprovado em 16/Nov/2005 